\title{
Properties of sulfur-extended asphalt concrete
}

\author{
Vitaliy Gladkikh ${ }^{1,}$, Evgeniy Korolev ${ }^{1}$, Dmitrij Husid ${ }^{1}$, Ilya Sukhachev $^{2}$ \\ ${ }^{1}$ Moscow State University of Civil Engineering, Nanomaterials and Nanotechnology Research and \\ Educational Centre, Yaroslavskoye hw. 26, 129337, Moscow, Russian Federation \\ ${ }^{2}$ Tuymen Industrial University, Volodarskogo st., 38, 625000, Tyumen, Russian Federation
}

\begin{abstract}
Currently, increased functional reliability of asphalt concrete coatings associated with various modifying additives that improve the durability of pavements. Promising builder is a technical sulfur. Asphalt concrete, made using a complex binder consisting of petroleum bitumen and technical sulfur, were calledsSulfur-Extended Asphalt Concrete. Such asphalt concrete, due to changes in the chemical composition of particulate and bitumen, changes the intensity of the interaction at the interface have increased rates of physical and mechanical properties. There was a lack of essential knowledge concerning mechanical properties of the sulfurbituminous concrete with such an admixture; therefore, we had carried out the necessary examination. It is revealed that a new material satisfies local regulations in terms of compressive and tensile strength, shear resistance, and internal friction.
\end{abstract}

\section{Introduction and prior work}

As practice shows asphalt coating around the world deformed and destroyed before the put and the warranty period and, as a rule, need to be repaired after the first years of operation. The causes of premature destruction and deformities include: high traffic, increasing axial loads, a violation of technology and the production of construction, as well as the poor quality of materials used.

One of the solutions to the problems of extending the service life of road surfaces associated with the task of obtaining the material, operate reliably in a change from positive to negative temperatures on the other hand, under the influence of intense traffic.

Increased functional reliability of asphalt concrete coatings currently in the Russian Federation and abroad associated with various modifying additives that contribute to improve the quality of road surfaces. Among such modifiers, include thermoplastic resin, rubber crumb, and others [1-4]. There exist numerous ways to improve the operational properties of concretes based on thermoplastic binder. By means of application of polymers distributed on the surface of fine filler it is possible to outcome several drawbacks of the traditional material with thermoplastic matrix [5-6]. The disadvantage of such approach is the consequence of extra processing stage during preparation of concrete mix.

The bitumen matrix of the asphalt concrete can be enhanced by polyolefins. In particular, addition of the grinded polyethylene decreases penetration increases the

* Corresponding author: gladkich_87@,mail.ru 
softening and melting points [7, 8]. As a consequence, the resulting material is characterized by increased rutting resistance and durability. However, admixture of polyolefins makes the production more complex and costly.

One of the most promising admixtures for the asphalt concrete is technical sulfur. Complex of operational properties of sulfur-based and sulfur-extended building materials may lead both to economical efficiency of construction and to reduce load on the environment. The feasibility of the sulfur-extended materials is primarily caused by properties, availability, and low cost of sulfur.

Today, technology of sulfur-bituminous materials develops intensively in different countries. Asphalt modified with sulfur, due to several factors (changes in the chemical composition of bitumen and varying the intensity of the interaction at the interface boundaries) is characterized by increased values of operational properties at elevated temperatures, especially - by high resistance to rutting. The long-term water resistance is also at high level for concretes with binder that includes no more than $45 \%$ of sulfur [9].

The sulfur-extended asphalt concretes often have to be characterized by an improved technical and economical efficiency; their usage leads to several benefits: increasing the material's application area, lowering the pollution of the environment (technical sulfur can be considered a waste because in Russia there are numerous sulfur dumps near the oil industry enterprises), decreasing the costs of construction and exploitation of roads (due to long periods between maintenance works).

The main factor limiting the widespread practical use of the mentioned technology was the lack of solutions to neutralize toxic gasses - hydrogen sulfide and sulfur dioxide formed during the manufacture and installation of sulfur-bituminous concrete. It was shown [10] that oxides of amphoteric metals are effective suppressors for hydrogen sulfide and sulfur dioxide. The obtained experimental data allowed the selection of most prospective suppressors for toxic gasses emitted during the production and laying of sulfur-bituminous concrete.

But till now, there was limited knowledge about physical and mechanical properties of the concrete with sulfur-bituminous matrix and aforementioned suppressors.

\section{Experimental setup}

The standard samples of asphalt concrete were prepared according to RU GOST 12801 from the concrete mixes with different amount of sulfurs $(20 \%-45 \%)$. Quality of the concrete mixes was determined according to RU GOST 31015. The prepared samples were examined for physical-mechanical and operational properties according to RU GOST 12801 (crack resistance), AASHTO TP 63-06 (resistance to rutting), and EN 12697-24 (fatigue life).

Cylindrical specimens of diameter $150 \mathrm{~mm}$ and height $75 \mathrm{~mm}$ (AASHTO TP 63 test) were compacted with Uniframe device. Six specimens for each composition of asphalt concrete were tested. The value of rut depth for each composition is calculated as an average for the six specimens.

\section{Results and discussion}

One of the most important mechanical properties of any building material is compressive strength. Experimentally obtained dependencies between the amount of sulfur-based admixture and compressive strength are shown in Fig. 1. 


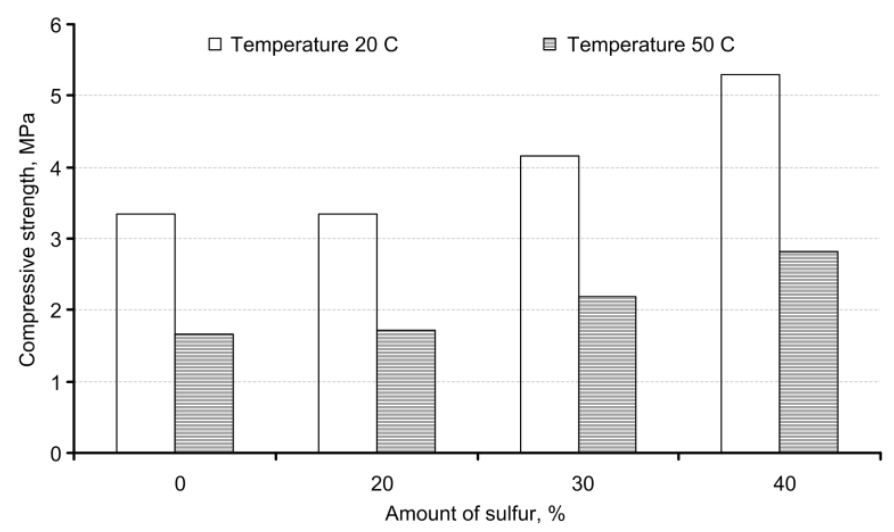

Fig. 1. Compressive strength of sulfur-bituminous pavement.

As it follows from Figure 1, addition of the small amount of sulfur does not change the compressive strength. Starting from concentration of $20 \%$, there is a linear dependence between compressive strength and amount of sulfur. Adding the sulfur notably alters the properties of the asphalt binder (the concentrations above $40 \%$ can not be used in practice because several other operational properties of the concrete are out of allowed limits). Such behavior is observed for both temperatures of experiment $\left(20\right.$ and $\left.50{ }^{\circ} \mathrm{C}\right)$.

This can be described as follows. Part of the sulfur is dispersed in the bitumen and leads to only a small improvement of the properties. Another part of the sulfur (when concentration is about $20 \%$ and higher) is undissolved and coagulates. Formation of large sulfur droplets takes place; these droplets crystallize upon cooling. The additional links of the crystallization are formed and because of this there is a hardening of asphalt material. At the operating temperatures (both 20 and $50{ }^{\circ} \mathrm{C}$ ), sulfur is solid and plays the role of disperse filler. This filler organizes the structure of the bitumen and increases thermal stability, rigidity, and resistance to rutting of asphalt concrete.

At the technological temperatures, sulfur is a highly mobile melt and increases the efficiency of mixing and laying of asphalt concrete mixes; thus, the goals of two different aforementioned groups are achieved simultaneously.

There is one operational property that is tightly correlated with mechanical properties resistance to rutting. Low values of rutting resistance significantly reduce durability of the pavement under load of heavy vehicles.

The experimental dependencies between number of processing cycles (according to AASHTO TP 63 test procedure) and depth of the rut are presented in Figure 2. 


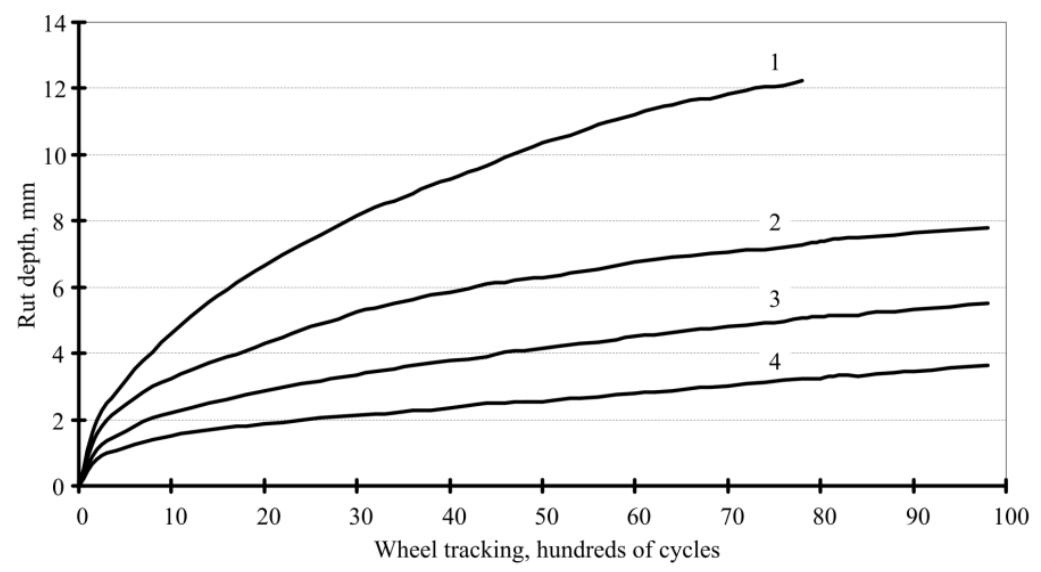

Fig. 2. Dependencies between the rut depth and number of wheel cycles for AASHTO TP 63 test and amount of sulfur: $1-0 \% ; 2-20 \% ; 3-30 \%, 4-40 \%$.

As it follows from Figure 2, even the small amount of sulfur significantly increases rutting resistance. Therefore, the area of primary application of sulfur-bituminous concrete is the construction of pavements with heavy load.

Material's fatigue life, together with rutting resistance, is the primary indicator of suitability for durable and long-life pavement. It is found during the study of fatigue life by means of multiple cyclic loading with indirect tensile scheme that designed sulfurbituminous materials are of high resistance (Figure. 3).

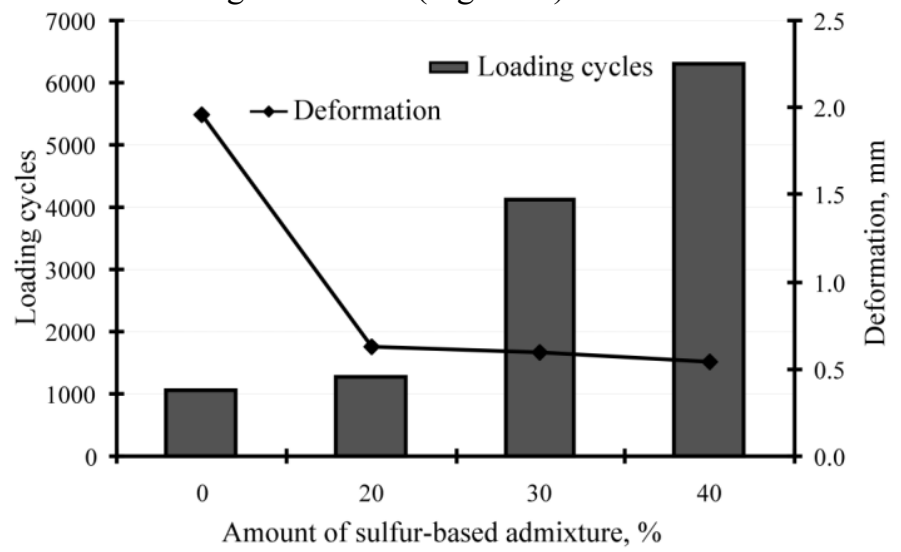

Fig. 3. The dependencies between fatigue limit, horizontal deformation and number of load cycles for different amounts of sulfur-based modifier.

It is clear from the experimental data in Figure 3 that fatigue life increases together with amount of sulfur in sulfur-bituminous mix. As before, starting from $20 \%$ concentration, we can observe linear dependence between operational property (in this case - fatigue life) and concentration. The number of cycles preceding the start of irreversible deformation induced by main crack grow, if compared with such number for reference sample, increases significantly for compositions with $30 \%$ and $40 \%$ of sulfur-based modifier (about 4 and 6 times, respectively). At the same time, enlargement of the content of sulfur modifier leads to decrease of deformability. 
So far, all the obtained data clearly demonstrate that there is the ultimate way for production of advanced pavement material - namely, complete elimination of bitumen. Obviously, such a conclusion would be wrong. Some consequences of such decision were already mentioned, and necessity of massive modification in current production facilities is not the only reason for that. Several important operational properties (e.g., water and frost resistance) are negatively affected by excess of the sulfur. Moreover, not every mechanical characteristic are in a positive correlation with amount of sulfur in bitumen. One of such properties is crack resistance. This parameter can be characterized by experimentally obtained values for splitting tensile strength at $0{ }^{\circ} \mathrm{C}$.

Properties of the sulfur-bituminous materials are summarized in Table 1.

Table 1. Properties of the developed sulfur-bituminous concrete.

\begin{tabular}{|c|c|c|c|c|c|}
\hline & RU & \multirow{2}{*}{ Reference } & \multicolumn{3}{|c|}{$\begin{array}{c}\text { Modified concrete, sulfur } \\
\text { content: }\end{array}$} \\
\cline { 4 - 6 } & GOST & sample & $\mathbf{2 0 \%}$ & $\mathbf{3 0 \%}$ & $\mathbf{4 0 \%}$ \\
\hline $\begin{array}{c}\text { Compressive } \\
\text { strength at 20 } \\
{ }^{0} \mathrm{C}, \mathrm{MPa}\end{array}$ & $>2.2$ & 3.3 & 3.3 & 4.2 & 5.3 \\
\hline $\begin{array}{c}\text { Compressive } \\
\text { strength at 50 } \\
{ }^{0} \mathrm{C}, \mathrm{MPa}\end{array}$ & $>0.65$ & 1.67 & 1.72 & 2.19 & 2.82 \\
\hline $\begin{array}{c}\text { Average } \\
\text { density, kg/m }\end{array}$ & - & 2620 & 2640 & 2650 & 2650 \\
\hline $\begin{array}{c}\text { Clutch shear } \\
\left(50^{\circ} \mathrm{C}\right), \mathrm{MPa}\end{array}$ & $>0.18$ & 0.29 & 0.29 & 0.38 & 0.54 \\
\hline $\begin{array}{c}\text { Water } \\
\text { resistance }\end{array}$ & $>0.85$ & 0.90 & 0.89 & 0.95 & 0.90 \\
\hline
\end{tabular}

The experimental results summarized in Table 1 show that compressive strength of sulfur-bituminous concrete at temperatures 20 and $50{ }^{0} \mathrm{C}$ exceeds not only the corresponding values for reference concrete without sulfur, but also the values required by RU GOST 31015.

It was also revealed during additional examination that sulfur-bituminous concrete after storage in water shows very low absorption. The absorption is 1.5-1.8 times lower if compared with reference composition. Therefore, freezing and thawing causes only a small negative effect if compared with conventional asphalt concrete. It is established that under identical operating temperatures the modulus of elasticity of sulfur-bituminous concrete is higher than modulus of conventional asphalt concrete. Moreover, with increasing temperature this difference also increases.

\section{Summary and conclusion}

In the present work, we have discussed the results of several laboratory tests. The tests were carried out to answer the question concerning dependence between the amount of sulfur-based modifier, mechanical and important operational properties of sulfurbituminous concrete for pavements.

It is shown that low amounts of sulfur are dissolved in bitumen, the compressive strength of concrete with such matrix is close to the strength of reference sample. Extra amounts of sulfur may lead to the formation of additional spatial cross-linked network. The formation of such a network, in turn, causes the increase of both strength and modulus of the concrete; rutting resistance also increases significantly. Thus, almost all the mechanical properties, including compressive strength and resistance to rutting, are positively 
correlated with concentration of designed multifunction sulfur-based admixture. Taking into consideration values of such properties as crack resistance (especially at low temperatures), water and frost resistance, and also such factors as necessity for preservation existing production infrastructure, the recommended amount of sulfur-based admixture with gas-suppression additives is about $30-40 \%$.

This work is supported by grant of Russian Federation President GP-2627.2016.1.

\section{References}

1. V.G. Nikolsky, I.A. Krasotkina, Automotive roads 2, 37-40, (2010)

2. A.B. Solomentsev, Science and Technology for Road Construction 1, 14-16, (2008)

3. L.M. Gochman, Pavements based on Sulfur-Extended Asphalts with Polymers (Infoavtodor, Moscow, 2002)

4. M.A. Vysotskaya, D.A. Kusnetsov, Building Materials 12, 63-64 (2013)

5. E.V. Korolev, V.A. Smirnov, A.I. Albakasov, Nanotechnologies in Construction 4, 8187, (2012)

6. E.V. Korolev, S.S. Inozemcev, Vestnik MGSU 10, 131-139 (2013)

7. T. Ali, N. Iqbal, M. Ali, K. Shahzada, IOSR-JMCE 5 1-6 (2014)

8. P. Shedame, N. Pitale, IOSR-JMCE 3, 37-45 (2014)

9. V.A. Gladkikh, E.V. Korolev, Vestnik MGSU 4, 76-83 (2013)

10. V.A. Gladkikh, E.V. Korolev. Advanced Materials Research 1040, 387-392 (2014) 